\title{
Localized Non-Hodgkin's Lymphoma of the Adrenal and Thyroid Glands
}

\author{
NILGÜN BASKAL, GÜRbÜZ ERDOGAN, A. NURI KAMEL, \\ S. SEN DAGCI, SERDAR AKYAR, AND CEMIL EKINCI \\ Departments of Endocrinology and Metabolic Diseases, Radiology \\ and Pathology, University of Ankara, Faculty of Medicine, \\ Avicenna Hospital ANKARA-TURKEY 06100
}

\begin{abstract}
A case of immunoblastic lymphoma, involving only the thyroid and the adrenal glands, is presented. The patient had clinical symptoms and findings of Addison's disease, and computed tomography (CT) demonstrated bilateral adrenal tumoral enlargement. He also had euthyroid diffuse multinodular goiter. The diagnosis of the patient was based on the cytological examination of the aspiration materials from both endocrine glands. The patient received " $m$-BNCOD" chemotherapy regimen and replacement therapy for Addison's disease. At the end of three courses, a partial response was obtained.
\end{abstract}

Key words: Non-Hodgkin lymphoma, Adrenal, Thyroid, Addison's disease.

(Endocrinol Japon 39: 269-276, 1992)

NON-HODGKIN'S lymphomas (NHL) involve extralymphatic sites more often than does Hodgkin's lymphoma; consequently tumor involvement of almost every abdominal organ has been recorded [1-6]. Secondary involvement of the adrenal gland with NHL has been reported to occur frequently [6-9]. The adrenals may contain heterotopic lymphoid elements that may be involved intrinsically in lymphoma [7]. However, primary lymphomas arising in the adrenal gland are extremely rare. Up to the present, only sixteen cases have been reported (Table 1) [8-11, 17-22]. Primary malignant lymphoma in the thyroid gland is rare but more common than in the adrenals. It has been reported that this disease accounts for $1.8-8.0 \%$ of all thyroid malignancies [12-15]. Up to date, no NHL involving primarily both the thyroid and the adrenal glands has been reported. In this report, we present a patient with bilateral adrenal masses and multinodular goiter. This will

Received: January 16, 1992

Accepted: April 17, 1992

Correspondence to: Dr. Nilgün BASKAL, Ankara Üniversitesi, Tip Fakültesi Endokrinoloji ve Metabolizma Hast, Bilim Dali. Ibn-i Sina Hastanesi, ANKARA-TURKIYE. be the first reported case of NHL so far primarily involving the adrenal glands and thyroid gland.

\section{Case Report}

A 49-year-old man, suffering from weakness, nausea, vomiting, weight loss and bouts of abdominal pain consulted a local clinic in December, 1988. His erythrocyte sedimentation rate was increased, he had hyponatremia and hyperkalemia. Computed tomography (CT) revealed big masses in the adrenals. He was admitted to the Endocrinology and Metabolic Diseases Department of the Faculty of Medicine of Ankara University for further evaluation in April, 1989. His past medical history included a peptic ulcer. Physical examination revealed an arterial blood pressure of $95 / 65 \mathrm{~mm} \mathrm{Hg}$, a pulse of 112 beats per min and a temperature of $36.7^{\circ} \mathrm{C}$ measured orally. He was $164 \mathrm{~cm}$ in height and weighed $64 \mathrm{~kg}$. Skin turgor was normal and he had mucocutaneous hyperpigmentation. He had multinodular goiter and his nodules were localized at both lobes and the isthmus of the thyroid gland. They were $2.5 \times$ 
Table 1. Reported primary adrenal NHL cases and their characteristics

\begin{tabular}{rcccccc}
\hline Case no & Age & Sex & Location & Type & Cell & Reference \\
\hline 1 & 52 & F & B & LS & ND & 8 \\
2 & 56 & F & B & LS & ND & 8 \\
3 & 71 & M & B & LS & ND & 8 \\
4 & 70 & M & B & LS & ND & 8 \\
5 & 39 & F & L & DL & B-cell & 8 \\
6 & 45 & M & L & DL & B-cell & 8 \\
7 & 81 & M & B & DL & B-cell & 10 \\
8 & 43 & M & B & DH & ND & 9 \\
9 & 62 & M & L & DM & B-cell & 22 \\
10 & 74 & M & B & DL & T-cell & 17 \\
11 & 67 & M & L & DM & T-cell & 11 \\
12 & 57 & M & B & DL & ND & 18 \\
13 & 68 & M & R & LI & B-cell & 19 \\
14 & 68 & M & B & DM & B-cell & 20 \\
15 & 68 & M & R & LI & B-cell & 8 \\
16 & 64 & F & R & DL & B-cell & 21 \\
17 & 49 & M & B & LI & ND & Present case \\
\hline
\end{tabular}

$\mathrm{L}$, indicates left adrenal gland only; $\mathrm{R}$, right adrenal gland only; B, both adrenal glands; M, male; F, female; ND, not done; DL, diffuse large cell; DM, diffuse mixed large and small cell; DH, diffuse histiocytic; LI, large cell immunoblastic and LS, lymphosarcoma.

$2 \mathrm{~cm}, 0.5 \times 1 \mathrm{~cm}$, and $0.5 \times 0.5 \mathrm{~cm}$ in size. No adenopathy, hepatosplenomegaly, ascites or edema was noted. There was moderate tenderness of the abdomen and bilateral costolomber regions. Other systemic examinations were normal.

His peripheral blood count, bone marrow biopsy and aspirate were within normal limits and the erythrocyte sedimentation rate was $160 \mathrm{~mm}$ at the end of one hour. His serum glucose, blood urea nitrogen, creatinine, bilirubin, cholesterol, triglycerides, serum glutamic oxaloacetic transaminase, serum glutamic pyruvic transaminase, natrium, calcium and phosphate levels were all normal. The alkaline phosphatase level was mildly and serum potassium level was moderately increased but the lactic dehydrogenase level was prominently increased. His protein electrophoresis showed low albumin, moderately high gamma-globulin and prominently high alpha-1, alpha-2 globulin fractions. His basal plasma cortisol level was low and the plasma adrenocorticotropic hormone (ACTH) value was high. In addition, there was no response to stimulation with ACTH (Table 2). His free thyroxine (free $\mathrm{T}_{4}$ ), free triiodothyronine (free $\mathrm{T}_{3}$ ) and thyrotropin (TSH) determinations and TSH responses to thyrotropin-releasing hormone (TRH) stimulation were
Table 2. Results of the ACTH stimulation test

\begin{tabular}{cccc}
\hline Time & $\begin{array}{c}\text { ACTH } \\
(\mathrm{pg} / \mathrm{m} l)\end{array}$ & $\begin{array}{c}\text { Plasma cortisol } \\
(\mu \mathrm{g} \%)\end{array}$ & $\begin{array}{c}\text { Free cortisol } \\
(\mu \mathrm{g} \%)\end{array}$ \\
\hline 0 & 213.8 & 1.0 & 0.8 \\
1st h & - & 1.0 & - \\
4 th h & - & 1.0 & - \\
6th h & - & 1.2 & - \\
Day 1 & - & 1.1 & 2.3 \\
Day 2 & - & 1.4 & 2.3 \\
Day 3 & - & 2.5 & 4.0 \\
\hline
\end{tabular}

within normal limits, whereas anti-microsomal antibody was negative. Plasma cortisol urinary free cortisol and free $T_{3}$ levels were determined by the Amersham RIA technique. For free $\mathrm{T}_{4}, \mathrm{TSH}$, Anti-M, Anti-Tg and ACTH determinations, Clinical Assays (Two step) RIA, IDS-IRMA (monoclonal antibody coated tubes), Henning (Promakassay)-IRMA, Henning (Thyrek-assay) IRMA and ICN-Double antibody-RIA methods were used, respectively.

His thyroid gland was examined by ultrasonography (US). US revealed hypoechoic nodular thyroid hyperplasia (Fig. 1A). These nodules were found to be hypoactive with Technetium 99-m thyroid scanning. His thyroid iodine $\left(\mathrm{I}^{131}\right)$ uptakes were low, thyroglobulin ( $\mathrm{Tg}$ ) was within normal limits but anti-Tg was negative. Fine-needle aspiration biopsy was performed on the thyroid nodule. Cytological evaluation of this first aspiration revealed thyroid acinus cells, some with oncocytic metaplasia and lymphoid cells of normal appearance and in different maturation stages. As he had a history of peptic ulcer and abdominal discomfort, endoscopy was performed before replacing with steroids and a healed duodenal ulcer was observed. On rectoscopic examination, he was found to have active haemorroids. There was no evidence of involvement of the small intestine and or the colon in X-ray studies. An intravenous pyelogram showed normal renal function, but the right kidney was displaced downwards by the adrenal tumor. His thorax roentgenogram and CT scan were normal. Abdominal US and CT were repeated and the right adrenal gland was found to be $6 \times 8 \mathrm{~cm}$ and the left one $3.5 \times 5.5 \mathrm{~cm}$ in size (Fig. 2A). No other organomegaly or adenopathy was noted on computed tomographic scanning. CT-guided fine needle aspiration biopsy of the right adrenal gland revealed "Class V High Grade Immunoblastic Lymphoma” (Fig. 3). 


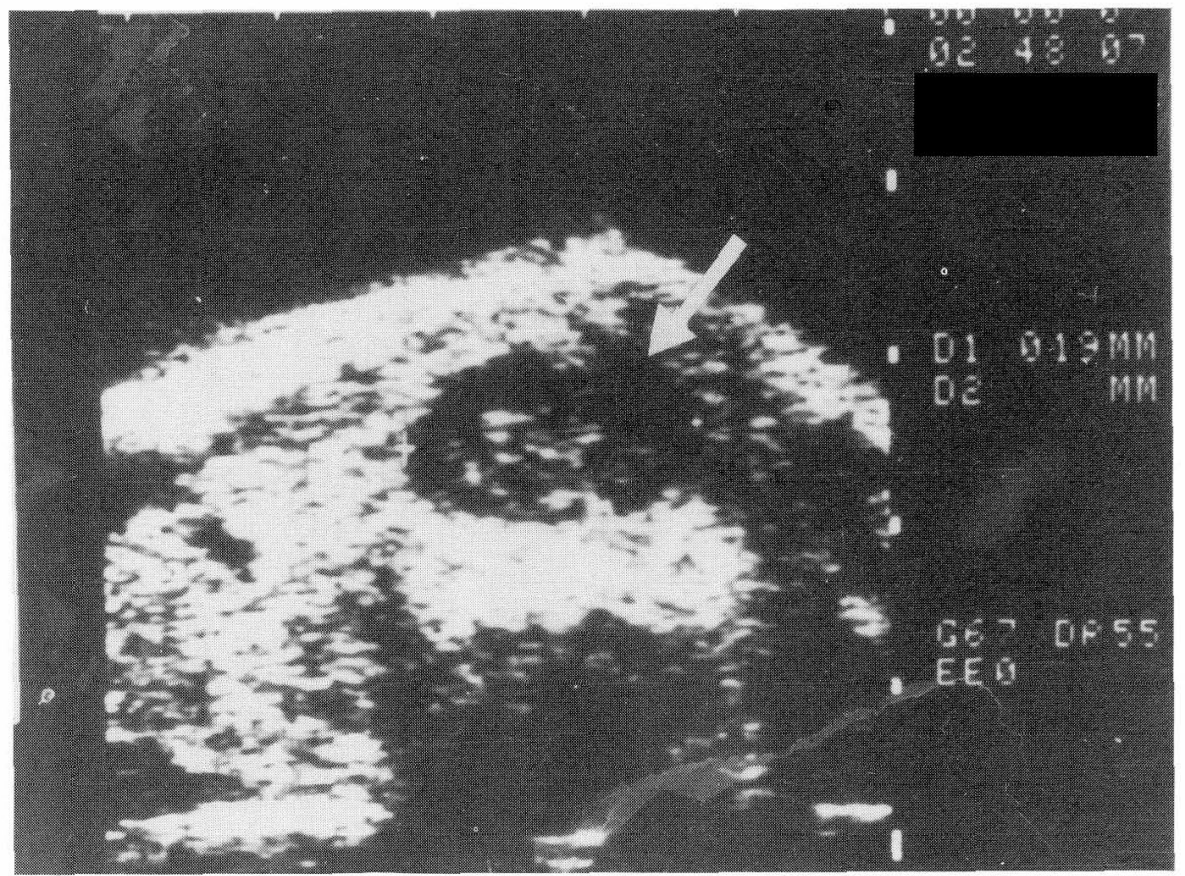

Fig. 1-A. Ultrasonographic photograph of the thyroid nodule before treatment (arrow). (It was examined with a Toshiba SAL-30 Lineer Array Real Time Ultrasonograph).

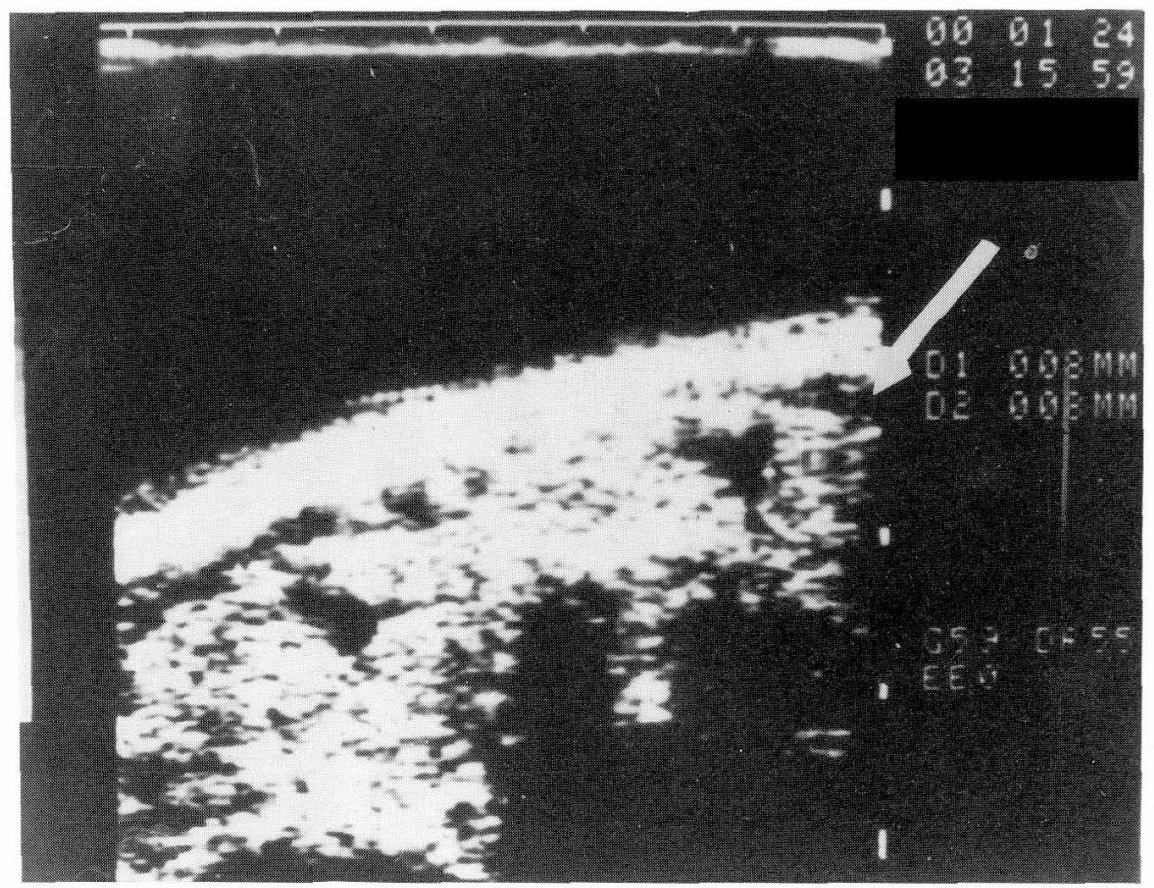

Fig. 1-B. Ultrasonographic photograph showing significant reduction in the sizes of the thyroid nodule after $\mathrm{m}$-BNCOD regimen (arrow). 


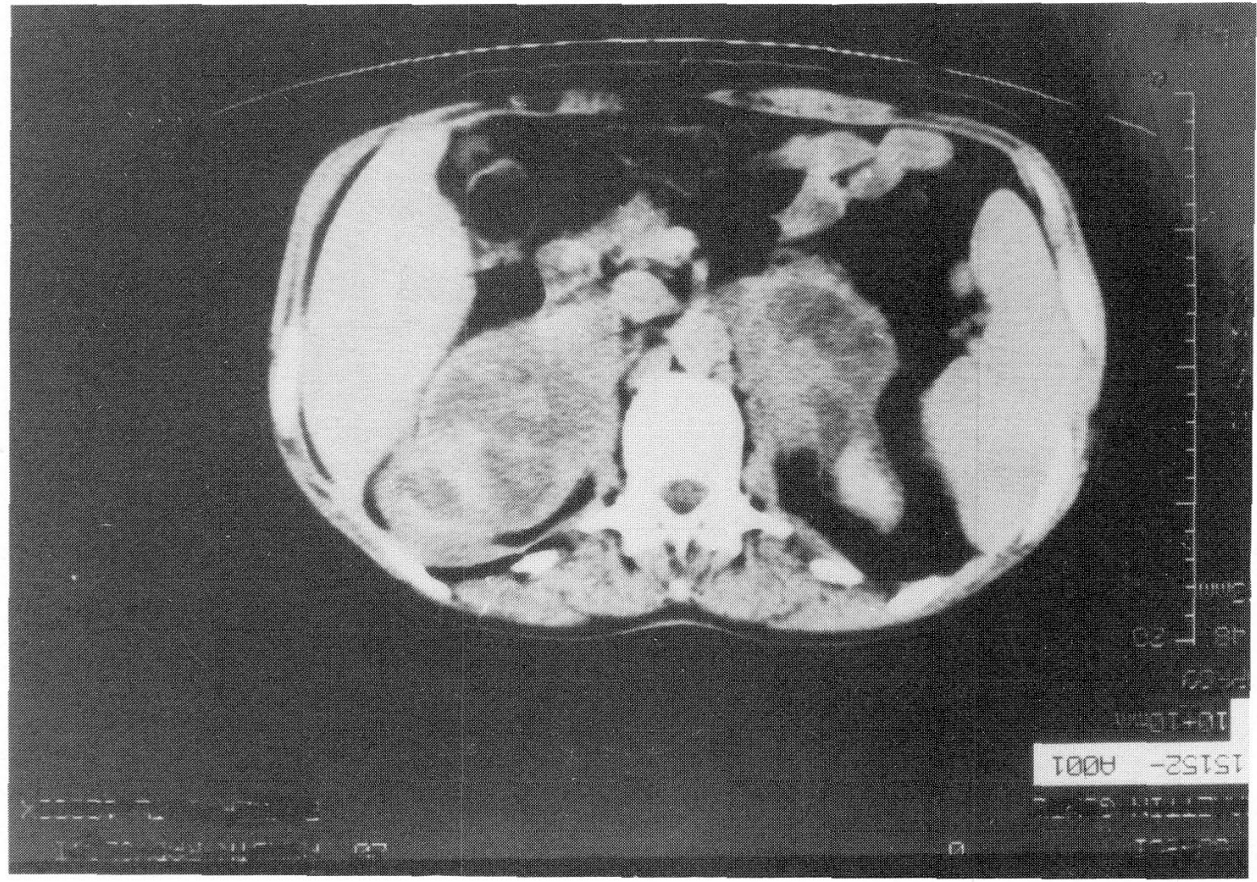

Fig. 2-A. Computed Tomographic scan photograph of the abdomen prior to chemotherapy: Bilateral adrenal masses without any enlargement in paraaortic lymph nodes. (It was examined with a Picker International 1200 SX, 4th generation CT).

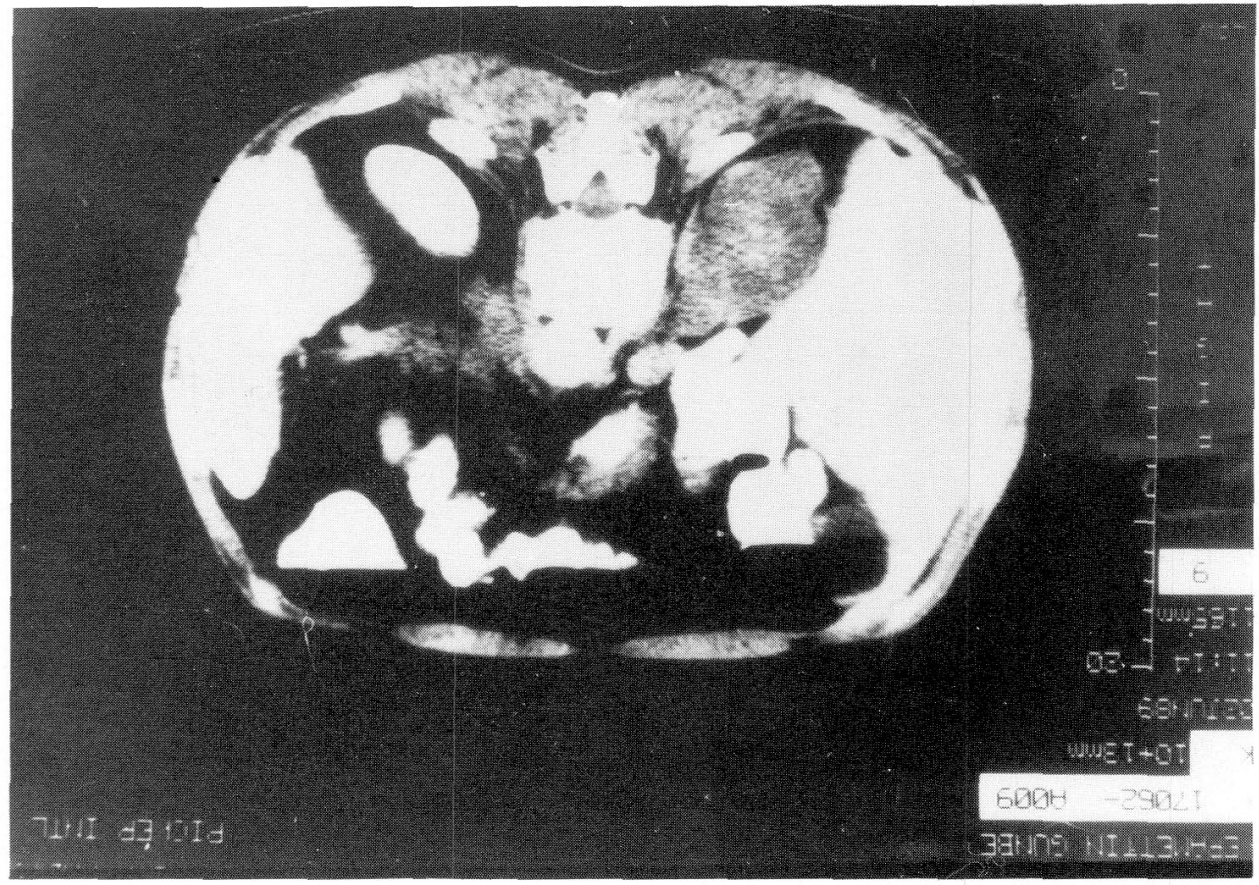

Fig. 2-B. CT scan at the end of third chemotherapy course with reduction in the size of adrenal masses up to $50 \%$. 


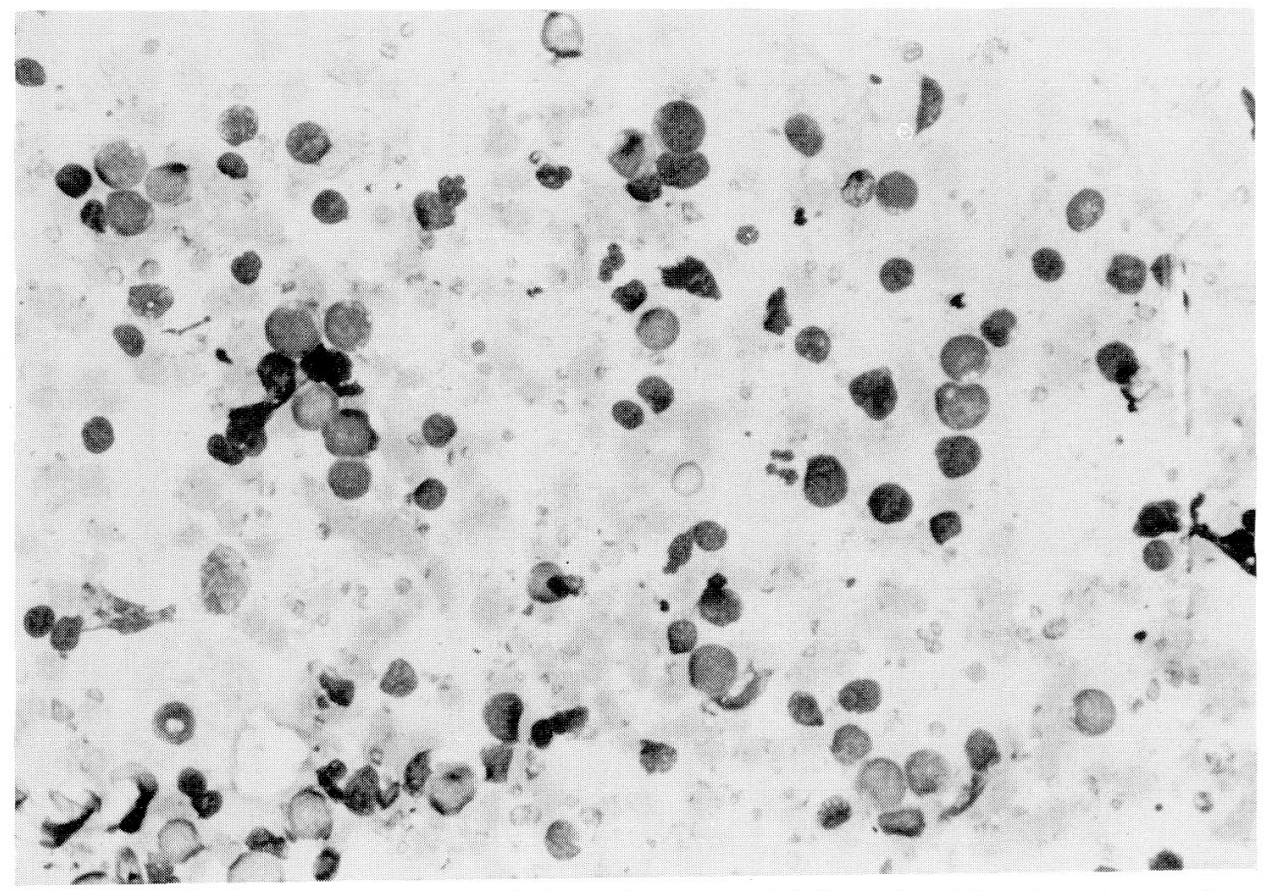

Fig. 3. The cytological examination of the aspirate material from the right adrenal mass. Note prominence of large hyperchromatic nuclcolated blastic lymphoid cells, with narrow basophylic vacuolated cytoplasm. (May Grünwald Giemza, 200×).

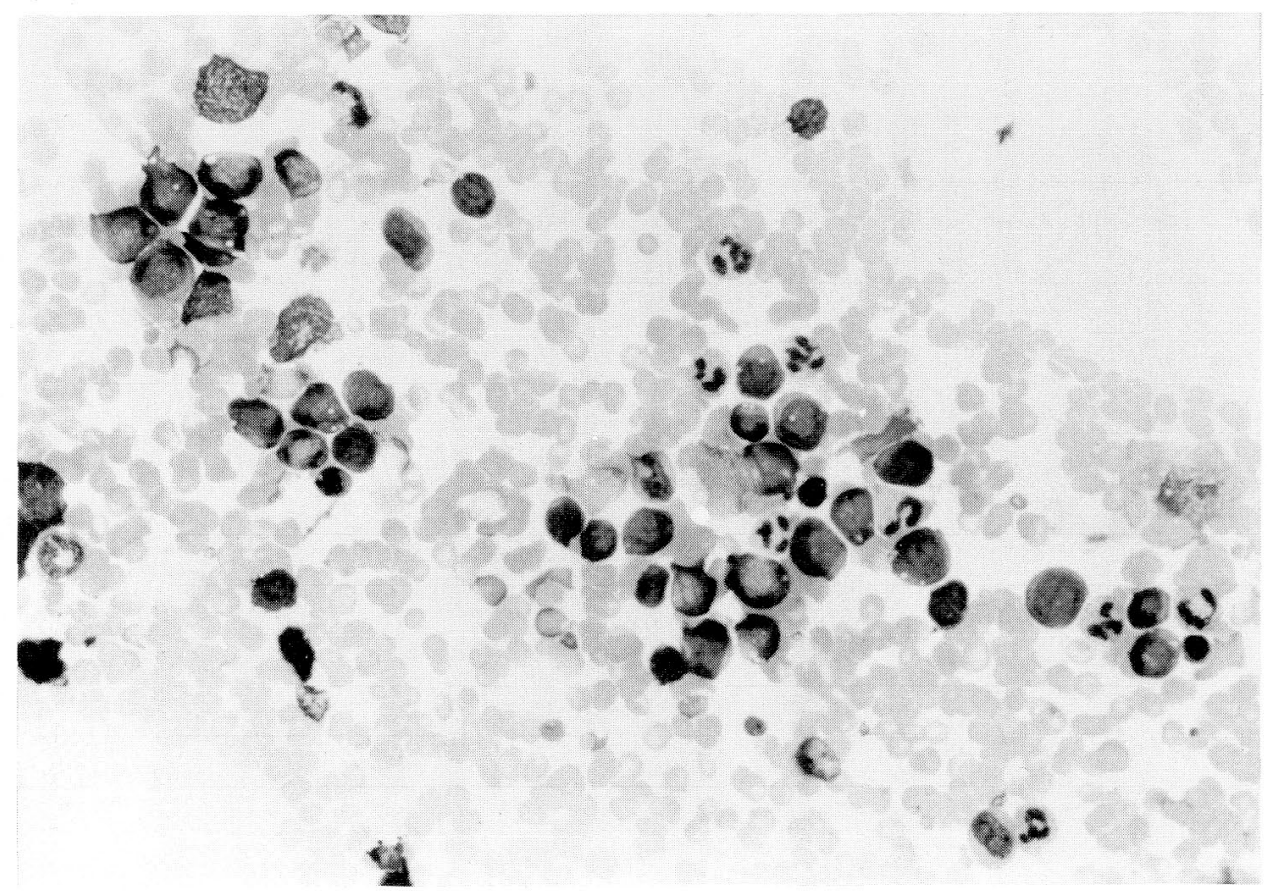

Fig. 4. The cytological evaluation of the second thyroid aspiration specimen. The large immunoblastic lymphoid cells with hyperchromatic nuclei are easily identified. (May Grünwald Giemza, 200x) 
Fifteen days after his admission, we observed that his thyroid gland and especially the nodules were enlarged in comparison to the previous measurements and so we reperformed fine needle aspiration biopsy. This aspiration specimen exhibited generally large, blastic lymphoid cells with hyperchromatic nuclei. The cytological diagnosis was "Class V High Grade Immunoblastic Lymphoma" as well (Fig. 4). Lymphangiography was carried out and it was observed that the lymphatic system had not been affected.

The lymphoma was decided to be localized primarily to both adrenal and thyroid glands, as no visceral or lymph nodal involvement was established by physical examination, conventional $\mathrm{X}$-ray studies mentioned above in detail, endoscopic examination, lymphangiography, US or CT.

Because of adrenal insufficiency, the patient was given $20 \mathrm{mg}$ hydrocortisone and $0.05 \mathrm{mg}$ fludrocortisone replacement daily. He was also treated with the "m-BNCOD" chemotherapy regimen [16]. The " $m-B N C O D "$ regimen is shown in Table 3. Dexamethasone $(9 \mathrm{mg} /$ daily) was given to the patient in accordance with this regimen. Hydrocortisone therapy had therefore been stopped during each course and was restarted later with the same dose. After 3 courses of the "m-BNCOD" regimen, he improved clinically and radiologically. His ACTH level was normalized, his skin pigmentation lightened, arterial blood pressure was about $110 / 70 \mathrm{~mm} \mathrm{Hg}$ and he gained weight. The nodules of the thyroid gland and the masses of the adrenal glands diminished in size significantly as demonstrated by US and CT scanning (Fig. 1B, 2B). He received the eight courses of chemotherapy and did not attain the follow-up controls. Unfortunately, in the 10 th month after the diagnosis we learned of the death of the patient from pneumonia at home. Autopsy could not be

Table 3. "m-BNCOD" chemotherapy regimen (Repeated at 4-week intervals)

\begin{tabular}{|c|c|c|c|}
\hline $\mathrm{m}$ & Methothrexate ......... & $200 \mathrm{mg} / \mathrm{m}^{2}$ days 1,8 & IV \\
\hline B & 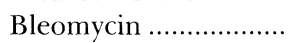 & $4 \mathrm{mg} / \mathrm{m}^{2}$ day 1 & IV \\
\hline$* \mathrm{~N}$ & Mitoxantrone. & $10 \mathrm{mg} / \mathrm{m}^{2}$ day 1 & Infusion \\
\hline $\mathrm{C}$ & Cyclophosphamide .... & $600 \mathrm{mg} / \mathrm{m}^{2}$ day 1 & IV \\
\hline $\mathrm{O}$ & 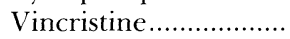 & $1 \mathrm{mg} / \mathrm{m}^{2}$ day 1 & IV \\
\hline $\mathrm{D}$ & Dexamethasone............. & $6 \mathrm{mg} / \mathrm{m}^{2}$ days 1,5 & Peroral \\
\hline
\end{tabular}

* As Adriamycin has cardiotoxic effects, Mitoxantrone which is a new Anthracycline derivative, not having much serious side effects, was used instead. performed because his family objected to it.

\section{Discussion}

Addison's disease may result from several etiologic factors. Among these, autoimmunity and tuberculosis are the two most important causes. On the other hand, some cases of Addison's disease may be of tumoral origin and they are relatively uncommon. However, it has been reported that secondary adrenal tumors including NHL can be seen rather frequently. Recently, the availability of CT and CT-guided aspiration biopsies have made a great contribution to the diagnosis of Addison's disease of tumoral origin. In contrast to secondary NHL of the adrenal glands, primary NHL has seldom been reported [8-11]. Primary adrenal lymphoma is more common in males, the male to female ratio being $12 / 4$. The age range is 39 to 81 years old. Only 16 cases of primary NHL of the adrenal gland have been reported in the last 43 years (Table 1), Four of them (cases 1-4, reported between 1948 and 1971) were diagnosed by autopsy, and several diagnostic methods were used for the other 12 (reported since 1983). Seven of them (Cases 5, 6, 9, 11, 13, $15,16)$ had unilateral and five of them (Cases 7,8 , $10,12,14)$ had bilateral involvement. In the present case, lymphoma developed both in the adrenals and the thyroid gland simultaneously. As seen clearly from the review of the reported cases, this is an extremely uncommon presentation of the primary lymphoma. Malignant (neoplastic) angioendotheliomatosis which is characterized by multifocal intravascular proliferation of malignant cells also may be another rare cause of Addison's disease [23-24]. But, because of its extremely different and peculiar clinical appearance with the dominance of cutaneous and neurologic manifestations, we didn't need to evaluate our case from this point of view.

The pathological characteristics of the patients varied; for example, diffuse mixed large and small cells in three cases, diffuse large cells in six cases, large cell immunoblasts in two cases, diffuse histiocytes in one case and lymphosarcoma in four cases. Our case was a large cell immunoblastic lymphoma. As we mentioned, the definite diagnosis of our patient was made with fine needle aspiration biopsy and the staining of specimens 
was made by May Grünwald Giemza. We didn't perform another aspiration biopsy for immunostaining.

Similarly, primary malignant lymphoma of the thyroid gland is also a rare disorder and it accounts for $1.8-8.0 \%$ of all thyroid malignancies [12-14]. To our knowledge, there are no reports about the simultaneous appearance of primary thyroid and adrenal lymphoma. In our case no involvement of the other viscera and lymph nodes could be demonstrated as noted previously. Therefore, this was considered to be a case of primary thyroid and adrenal NHL.

Since the CT and US findings of adrenal lymphoma cannot be specific, CT-guided fine needle aspiration biopsy is usually determinative because of adrenal involvement. It would therefore be the method of choice in the definite diagnosis of such adrenal masses as in this case.

Some of the reported cases had been treated with surgery and/or chemotherapy with relatively poor outcomes. We attempted to give a specific chemotherapy program as well as a hormonal replacement regimen as noted above. A partial response was obtained by the end of three courses and the patient was followed up for 10 months with satisfactory improvement in his clinical condition and a substantial regression of the lesions in both endocrine glands.

In conclusion the following points cannot be overemphasized:

1. Primary NHL of the adrenals and the thyroid gland may be simultaneously encountered and the case presented here is very interesting with respect to this property.

2. Modern imaging techniques such as US and CT seem to be mandatory in the evaluation of cases with primary hypocortisolism in order to exclude the presence of adrenal masses responsible for Addison's disease.

3. The fine needle aspiration biopsy of adrenal masses with CT guidance would be definitely diagnostic. The proper cytological examination of the aspired material seemed to be sufficient for a correct diagnosis and the maintenance of suitable treatment.

\section{References}

1. Jones SE, Fuks Z, Bull M, et al (1973) NonHodgkin's Lymphomas: IV. Clinicopathological correlation in 405 cases. Cancer 31: 806-823.

2. Goffinet DR, Castellino RA, Kim H. (1973) Staging laparotomies in unselected previously untreated patients with non-Hodgkin's lymphomas. Cancer 32: 672-681.

3. Burgener FA, Hamlin DS (1981) Histiocytic lymphoma of the abdomen: Radiographic spectrum. AJR 137: 337-342.

4. Harell GS, Breiman RS, Glatstein EJ, Marshall WH, Castellino RA (1977) Computed tomography of the abdomen in the malignant lymphomas. Radiol Clin North Am 15: 391-400.

5. Goffinet DR, Warnke R, Dunnick NR (1977) Clinical and surgical (laparotomy) evaluation of patients with non-Hodgkin's lymphomas. Cancer Treat Rep 6: 981-992.

6. Paling MR, Williamson BRJ (1983) Adrenal involvement in non-Hodgkin lymphoma. AJR 141: 303-305.

7. Rumancik WM, Bosniak MA (1988) Nonfunctioning adrenal masses-Adrenal lymphomas. In: Putman CE, Ravin CE (eds) Textbook of Diagnostic Imaging. WB Saunders Philadelphia, 1st ed, vol. 2: 1152.
8. Harris GJ, Tio FO, Von Hoff DD (1989) Primary adrenal lymphoma. Cancer 63: 799-803.

9. Feldberg MAM, Hendriks MJ, Klinkhamer AC (1986) Massive bilateral non-Hodgkin's lymphomas of the adrenals. Urologic Radiology 8: 85-88.

10. Shea TC, Spark R, Kane B, Lange RF (1985) Non-Hodgkin's lymphoma limited to the adrenal gland with adrenal insufficiency. The American Journal of Medicine 78: 711-714.

11. Gondoh M, Sakamoto H, Fujii A (1987) A case of primary non-Hodgkin's lymphoma of left adrenal gland. Jpn Clin Radiol 32: 155-158 (In Japanese).

12. Takashima S. Ikezoe J, Morimoto S (1988) Primary thyroid lymphoma: Evaluation with CT. Radiology 168: 765-768.

13. Welch JW, Chesky VE, Hellwing CA (1958) Malignant lymphoma of the thyroid gland. Surg Gynecol Obstet 106: 70-76.

14. Heimann R, Vannineuse A, de Sloover C, Dor P (1978) Malignant lymphoma and undifferentiated small cell carcinoma of the thyroid: A clinicopathological review in the light of the Kiel classification for malignant lymphoma. Histopathology 2: 201213.

15. Souhami L, Simpson WJ, Carruthers JS (1980) Malignant lymphoma of the thyroid gland. Int $J$ 
Radiol Oncol Biol Phys 6: 1143-1147.

16. Skarin A, Canellos G, Rosenthal D (1983) Moderate dose methothrexate $(\mathrm{m})$ combined with bleomycine (B), adriamycin (A) cyclophosphamide $(\mathrm{C})$, oncovine $(\mathrm{O})$ and dexamethasone $(\mathrm{D})$; $\mathrm{m}$ BACOD in advanced diffuse histiocytic lymphoma (DHL). Proc Am Soc Clin Oncol 2: 220.

17. Schnitzer B, Smid D, Lloyd RV (1986) Primary T-cell lymphoma of the adrenal glands with adrenal insufficiency. Hum Pathol 17: 634-636.

18. Carey RW, Harris N, Kliman B (1987) Addison's disease secondary to lymphomatous infiltration of the adrenal gland. Cancer 59: 1087-1090.

19. Vicks BS, Perusek M, Johnson J, Tio F (1987) Primary adrenal lymphoma: CT and sonographic appearances. J Clin Ultrasound 15: 135-139.
20. Abe J, Kaneko H, Takagi A, Umezu H (1988) Primary adrenal lymphoma: Report of an autopsy case. Acta Pathol Jpn 38: 929-939.

21. Choi CM, Durishin M, Garbadawala ST, Richard J (1990) Non-Hodgkin's lymphoma of the adrenal gland. Arch Pathol Lab Med 114: 883-885.

22. Alonso I, Alvarz M, Margil MA, Serrano M (1986) Primary extralymph node lymphoma of the adrenal glands (letter). Med Clin (Barc) 86: 393-394.

23. Sheibani K, Batifora H, Winberg CD (1986) Further evidence that "Malignant Angioendotheliomatosis" is an angiotropic large cell lymphoma. New England Journal of Medicine 314, 15: 943-948.

24. Bhawan J, Wolff SM, Ucci AA, Bhan AK (1985) Malignant lymphoma and malignant angioendotheliomatosis: One disease. Cancer 55: 570-576. 